\title{
Analysis of weathering and internal texture on the engineering properties of granites
}

\author{
G. Vasconcelos \& P.B. Lourenço \\ Department of Civil Engineering, University of Minho, Guimarães, Portugal \\ C.S.A. Alves \& J. Pamplona \\ Department of Earth Sciences, University of Minho, Braga, Portugal
}

\begin{abstract}
The research significance of the present paper concerns the need of knowing the mechanical properties of stone existing in the ancient constructions, when a suitable methodology for their rehabilitation or strengthening is followed. The rehabilitation of ancient constructions, mainly the ones pertaining to the architectural heritage is a demand of modern societies. The deep knowledge of mechanical and fracture properties of the stone is also an important advantage, when structural analysis is needed for the evaluation of the safety conditions of ancient constructions. Thus, this paper aims at providing large information about the influence of factors such as weathering state and planar anisotropy on the engineering properties of Portuguese granites. It was found that both weathering and internal structure play a major role on the mechanical tensile and compressive behavior of granites. Besides, the non-destructive evaluation reveal as possible technique to predict the weathering and anisotropy of granites.
\end{abstract}

\section{INTRODUCTION}

Masonry is the oldest building material that survived until today, being used all over the world and being present in the most impressive historical structures as an evidence of spirit of enterprise of ancient cultures. Portugal is rich of monumental buildings and there is a considerable amount of existing residential masonry buildings in rural areas. Conservation, rehabilitation and strengthening of the built heritage and protection of human lives are clear demands of modern societies. This requires identification of deficiencies of existing structures and appropriate intervention techniques.

Being masonry a composite material, composed by units and mortar, its behavior necessarily depends on the mechanical properties of the components and on the masonry bond (arrangement of the stones). These aspects are considered using granitic stone from Portugal. In order to fully characterize the Portuguese granite, a comprehensive testing program was setup using destructive and non-destructive testing Vasconcelos (2005). The latter is of much relevance, as the collection of samples from existing buildings is expensive and, often, not possible.

Thus, the present article aims at giving an overview of the factors, weathering and planar anisotropy, which influences considerably the engineering properties resulting from compressive and tensile behavior of different granitic lithotypes.

The evaluation of the variation of the elastic and fracture properties as a function of the weathering and internal texture was made based on the results of an enlarged experimental program composed by direct tensile and uniaxial compressive tests carried out on the different types of granite. Additionally, the variation of the engineering properties was also assessed by means of the application of simple non-destructive tests, like ultrasonic pulse velocity and Schmidt hammer tests.

\section{DESCRIPTION OF THE MATERIAL}

A wide range of granitic rocks is present in masonry constructions, depending on their petrographic features, such as grain size and internal texture. Therefore, the mechanical characterization of only one type of granite would be rather limitative. In addition, the weathering processes, to which granites are subjected through years, lead to changes on the mechanical properties that require characterization. This issue is particularly relevant in case of ancient buildings.

The granites adopted in the present work were mostly collected from the Northern region of Portugal. The selection of the granitic types was based on the 
mineralogical composition and grain size, aiming at providing a comprehensive sample of the Portuguese granites. In addition to these criteria, the presence of preferential orientation planes and weathering condition were also taken into account.

It has been pointed out that the fabric, related to the arrangement and preferential orientation of minerals, represents a textural aspect that, in general, contributes to the variation of mechanical properties, including the strength (Tuğrul and Zarif, 1999; Åkesson et al., 2003). If some granitic rocks, by its random texture, are likely to have isotropic properties, a more careful analysis is needed when visual evidence of heterogeneities and preferential orientations of the minerals are detected. The latter assumptions, which were identified on some granitic lithotypes under study, led to the necessity of conducting mechanical tests according to different loading directions. Three orthogonal planes can be identified with rock splitting planes (quarry planes) defined as planes of preferred rupture. The rift plane is the plane corresponding to the easiest splitting in the quarry being easily recognized by the quarryman since it is further associated to the plane of easiest finishing. A brief description of the adopted different lithotypes is indicated in Table 1. The more weathered types of the same granite facies are distinguished with an asterisk (*). Additionally, the loading directions considered in the experimental program are also indicated. The orientation of the rift plane was marked with the help of a quarryman and, when visible in the macroscopic scale,

Table 1. Brief description of the selected granites.

\begin{tabular}{|c|c|c|}
\hline Granite & Petrologic description & Loading directions \\
\hline $\mathrm{BA}$ & $\begin{array}{l}\text { Fine to medium-grained } \\
\text { porphyritic biotite granite }\end{array}$ & $\begin{array}{l}\text { Parallel to the } \\
\text { rift plane }\end{array}$ \\
\hline $\begin{array}{l}\mathrm{GA}, \\
\mathrm{GA}^{*}\end{array}$ & $\begin{array}{l}\text { Fine to medium-grained, } \\
\text { with porphyritic trend, } \\
\text { two mica granite }\end{array}$ & $\begin{array}{l}\text { Parallel to the } \\
\text { rift plane }\end{array}$ \\
\hline RM & $\begin{array}{l}\text { Medium-grained biotite } \\
\text { granite }\end{array}$ & $\begin{array}{l}\text { Parallel to the } \\
\text { rift plane }\end{array}$ \\
\hline $\mathrm{MC}$ & $\begin{array}{l}\text { Coarse-grained porphyritic } \\
\text { biotite granite }\end{array}$ & $\begin{array}{l}\text { Parallel to the rift } \\
\text { plane }\end{array}$ \\
\hline $\mathrm{AF}$ & $\begin{array}{l}\text { Fine to medium-grained } \\
\text { two mica granite }\end{array}$ & $\begin{array}{l}\text { Parallel and } \\
\text { perpendicular to } \\
\text { the foliation plane }\end{array}$ \\
\hline $\begin{array}{l}\text { MDB, } \\
\text { MDB* }\end{array}$ & $\begin{array}{l}\text { Fine to medium-grained } \\
\text { two mica granite }\end{array}$ & $\begin{array}{l}\text { Parallel and } \\
\text { perpendicular to } \\
\text { the foliation plane }\end{array}$ \\
\hline $\begin{array}{l}\text { PTA, } \\
\text { PTA* }\end{array}$ & $\begin{array}{l}\text { Fine to medium-grained } \\
\text { two mica granite }\end{array}$ & $\begin{array}{l}\text { Parallel and } \\
\text { perpendicular to } \\
\text { the foliation/rift } \\
\text { plane }\end{array}$ \\
\hline $\begin{array}{l}\text { PLA, } \\
\text { PLA* }\end{array}$ & $\begin{array}{l}\text { Medium to coarse-grained } \\
\text { porphyritic biotite granite }\end{array}$ & $\begin{array}{l}\text { Parallel and } \\
\text { perpendicular } \\
\text { to the rift plane }\end{array}$ \\
\hline
\end{tabular}

* Weathered granites. the foliation plane, defined from the preferential orientation of the grains, was also marked.

In case of the granite is assumed homogeneous (random orientation of minerals), only the direction parallel to the rift plane was considered (granites BA, GA, GA*, $\mathrm{RM}, \mathrm{MC}$ ). If the granite presented visible foliation, the perpendicular and parallel directions to the foliation plane were considered (AF, MDB, MDB*, PTA). In granites PLA and PLA*, the preferred orientation of feldspar phenocrystals (flow structure) is subparallel to the rift plane and, consequently, two loading directions (parallel and perpendicular to the rift plane) were considered. As the more weathered granite PTA* does not show clear visible foliation, directions parallel and perpendicular to the rift plane were considered.

\section{EXPERIMENTAL TESTING}

\subsection{Specimens and test procedure}

As was intended to have the possibility to obtain the complete behavior of granite both under tensile and compressive loading and, thus, a complete overview of the engineering properties (elastic, strength and fracture properties), the testing equipment was carefully selected. The obtainment of softening stable behavior in rock materials is only possible by performing the tests under closed-loop control. For the direct tensile tests, a CS7400S servo-controlled universal testing machine with fixed end platens was used. This equipment has a load cell connected to the vertical actuator with a capacity of $22 \mathrm{kN}$, being particularly suitable for small specimens. Thus, due to the limited distance between platens, prismatic specimens of $80 \mathrm{~mm}$ height, $50 \mathrm{~mm}$ length and $40 \mathrm{~mm}$ width were adopted, see Figure 1. Such dimensions are less favorable in case of coarsegrained granites and granites with porphyritic texture, since larger representative material volume would be required ISRM (1981). To overcome this limitation, a higher number of specimens were tested, so that the
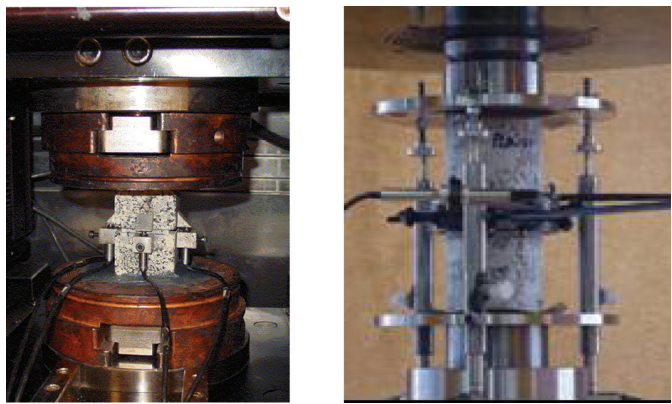

Figure 1. Test setup for uniaxial compressive and tensile direct tests. 
effect of the scatter in the results are reduced and the average values are representative of the macroscopic properties, especially in the case of granites PLA and PLA*. Since the control system allows only one Linear Variable Displacement Transducer (LVDT) as displacement control, it was decided to introduce, by means of a diamond sawing machine, two lateral notches with a depth of $5 \mathrm{~mm}$ at mid height of the specimen in order to localize the fracture path. The specimens were fixed to the steel platens through the application of an epoxy resin.

Due to the brittle behavior of granite, direct tensile tests had to be conducted using low values of velocity, which varied between $0.08 \mu \mathrm{m} / \mathrm{s}$ and $0.5 \mu \mathrm{m} / \mathrm{s}$.

The specimens to be tested under uniaxial compression were prepared in accordance with ASTM D2938 (1986) standard. A diameter of $75 \mathrm{~mm}$ was adopted for all specimens and the length to diameter ratio was slightly higher than 2.0. If, in general, such dimensions are clearly sufficient to be in agreement with the standard, for coarse-grained granites that exhibit porphyritic internal texture, the diameter is smaller than 10 times the largest grain. In the preparation of the specimens, special care was taken to ensure parallel ends and perpendicular to the longitudinal axis. In addition, the specimen ends were suitably ground so that a smooth surface could be obtained. The uniaxial compressive tests were carried out in a very stiff frame connected with an appropriate closed-loop control system. As among the granites to be tested, some of them, are expected to be high strength granites, the internal variable selected as feedback signal was the lateral displacement. In the absence of a circumferential extensometer, a special device was designed to measure the lateral deformations Vasconcelos (2005). In order to reduce the friction coefficient between specimens and steel platens, two sheets of Teflon with a thickness of $100 \mu \mathrm{m}$ were placed at the interfaces between the specimen and the steel platens, see Figure 1.

\subsection{Tensile and compressive mechanical properties}

Tensile and compressive mechanical properties were derived from the tensile force-displacement diagrams and from the stress-strain diagrams obtained in compression. The displacement of the crack opening of tensile specimens was calculated by averaging the results of four LVDTs placed at each side of the specimens. The strains of the compressive specimens were obtained by averaging the measurements of the three LVDTs placed $120^{\circ}$ apart between the upper and the lower steel platens. The Young modulus was calculated based on the strains measured by the two vertical strain gauges placed at mid height of the specimen.

The average mechanical properties, tensile strength, $\mathrm{f}_{\mathrm{t}}$, compressive strength, $\mathrm{f}_{\mathrm{c}}$, and Young modulus, $\mathrm{E}$, are summarized in Table 2. For the average, all specimens of each granite were taken into account. The coefficient of variation in percentage is indicated inside brackets. Information about the fracture properties, namely mode I fracture energy and compressive fracture energy, Poisson's ratio, details about the complete shape of the diagrams, failure modes and features of mode I fracture surfaces can be found in Vasconcelos (2005). From the analysis of the results, it can be observed that low to medium scatter is associated to the strength and elastic properties, even for the coarsed-graned granite PLA and PLA*.

A wide range of tensile and compressive mechanical properties and Young modulus was obtained for the granites under study. Besides the distinct petrographic characteristics that contribute for the variation on the mechanical properties, the internal texture and the weathering state are clearly important factors that help to explain the variation. A deeper analysis of the influence of these factors on the compressive and tensile behavior of granites, based on the qualitative analysis given by the complete force-displacement and stress-strain diagrams and from the comparative study of the mechanical properties, is provided in the next sections.

\subsection{Evaluation of the weathering sate}

An illustrative example of the influence of the weathering on the compressive behavior of granites in

Table 2. Mechanical properties of granites.

\begin{tabular}{llrl}
\hline Granite & $\begin{array}{l}\mathrm{f}_{\mathrm{t}} \\
\left(\mathrm{N} / \mathrm{mm}^{2}\right)\end{array}$ & $\begin{array}{l}\mathrm{f} \\
\mathrm{f} \\
\left(\mathrm{N} / \mathrm{mm}^{2}\right)\end{array}$ & $\begin{array}{l}\mathrm{E} \\
\left(\mathrm{N} / \mathrm{mm}^{2}\right)\end{array}$ \\
\hline $\mathrm{BA}$ & $8.08(11.4)$ & $148.5(4.8)$ & $59939(5.2)$ \\
$\mathrm{GA}$ & $6.01(11.1)$ & $135.7(5.0)$ & $52244(2.3)$ \\
$\mathrm{GA} *$ & $3.52(12.3)$ & $89.5(2.5)$ & $35088(3.3)$ \\
$\mathrm{RM}$ & $4.51(9.3)$ & $159.8(2.5)$ & $58926(1.8)$ \\
$\mathrm{MC}$ & $5.23(6.3)$ & $146.7(2.8)$ & $63794(5.6)$ \\
$\mathrm{AF} \perp \mathrm{fl}$ & $2.34(11.5)$ & $66.7(7.8)$ & $15748(7.2)$ \\
$\mathrm{AF} / / \mathrm{fl}$ & $3.04(3.0)$ & $68.9(5.6)$ & $18954(6.9)$ \\
$\mathrm{MDB} \perp \mathrm{fl}$ & $2.36(5.4)$ & $49.7(5.2)$ & $15886(13.5)$ \\
$\mathrm{MDB} / / \mathrm{fl}$ & $2.20(4.9)$ & $44.8(2.8)$ & $11600(4.2)$ \\
$\mathrm{MDB} * \perp \mathrm{fl}$ & $1.83(4.3)$ & $35.2(3.4)$ & $11028(12.0)$ \\
$\mathrm{MDB} * / / \mathrm{fl}$ & $1.97(5.3)$ & $26.0(7.1)$ & $12243(13.6)$ \\
$\mathrm{PTA} \perp \mathrm{fl}$ & $4.15(14.1)$ & $119.1(3.1)$ & $40526(3.1)$ \\
$\mathrm{PTA} / / \mathrm{fl}$ & $4.90(15.6)$ & $109.1(7.3)$ & $41504(1.6)$ \\
$\mathrm{PTA} * \mathrm{rp}$ & $1.56(11.3)$ & $60.4(4.8)$ & $15008(7.1)$ \\
$\mathrm{PTA} * / / \mathrm{rp}$ & $2.12(4.1)$ & $50.2(11.1)$ & $18168(3.3)$ \\
$\mathrm{PLA} \perp \mathrm{rp}$ & $2.79(10.5)$ & $147.0(2.6)$ & $53737(2.8)$ \\
$\mathrm{PLA} / / \mathrm{rp}$ & $6.31(13.2)$ & $125.2(6.1)$ & $58180(2.6)$ \\
$\mathrm{PLA} * \mathrm{rp}$ & $1.91(11.1)$ & $88.5(4.2)$ & $28981(1.6)$ \\
$\mathrm{PLA} * / / \mathrm{rp}$ & $3.86(5.1)$ & $76.9(3.2)$ & $41607(7.6)$ \\
\hline
\end{tabular}

rp - rift plane.

$\mathrm{fl}-$ foliation. 

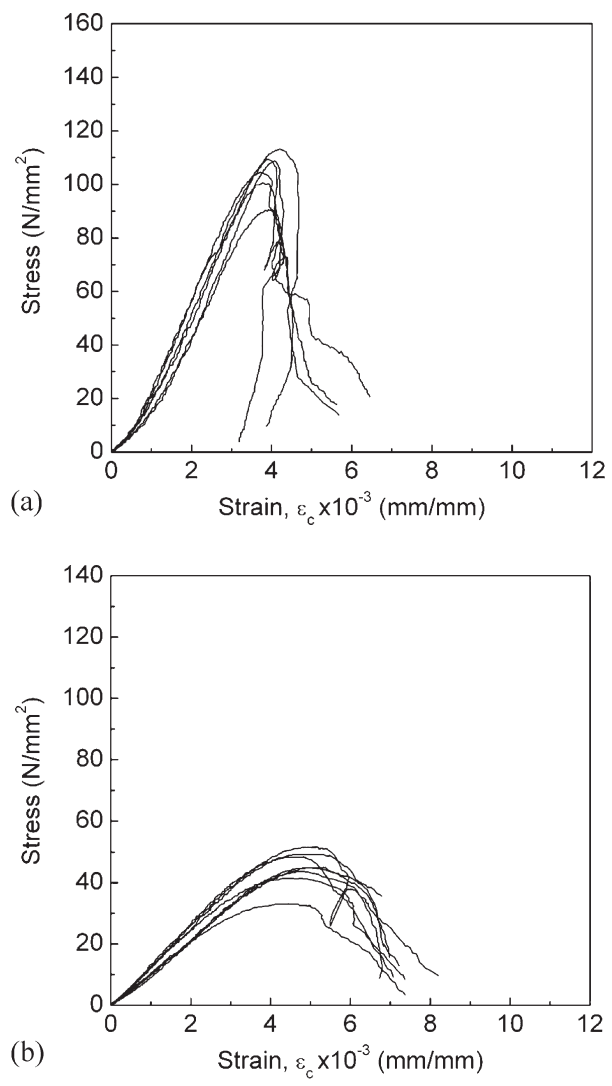

Figure 2. Stress-strain diagrams; (a) granite PTA in the direction parallel to the foliation; (b) granite PTA* in the direction parallel to the foliation.

given in Figure 2, where the stress-strain diagrams of granite PTA and PTA* are displayed.

The shape of these diagrams shows clearly that significant distinct pre- and post-peak compressive behavior is addressed for weathered and less weathered granites. Besides the higher values of the compressive strength, the slope of the ascending branch of the stress-strain diagrams is considerably higher in fresh granites, in comparison with the slope exhibited by weathered granites. Moreover, the deformation capacity until peak load is attained is significantly larger in weathered granites.

In terms of post-peak behavior it is noticeable that fresh granites exhibit very brittle response, associated to a steep and often discontinuous softening branch, whereas for weathered granites the descending branch is mostly continuous and smooth. The remarkable difference of the post-peak behavior seems to result from the distinct mechanism of macrocracking localization. In effect, in less weathered granites the main

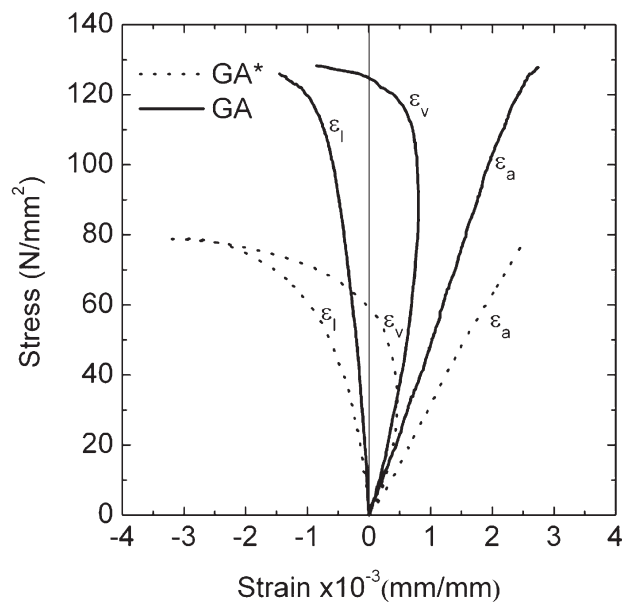

Figure 3. Comparison stress-volumetric strain and stressaxial strain of the pre-peak regime between granites GA and $\mathrm{GA}^{*}$.

macrocrack that result from the localization is parallel or sub-parallel to the axial load. In weathered granites the localization occurs predominantly in a shear band. The ultimate deformation is considerable higher in weathered granites, which appears as an outcome of a more ductile behavior of the material.

By comparing the modulus of elasticity, E, which mostly characterizes the pre-peak branch, it is clear that much higher values of the modulus of elasticity are associated to fresh granites. Nevertheless, the difference between the less weathered granite MDB and the weathered granite $\mathrm{MDB}^{*}$ is minimal. The main reasons that contribute for the decrease upon weathering are related to the lower stiffness of the rock forming minerals as a result of their alteration, as well as to progressive weakness of the bond interface stiffness.

The decrease in the compressive strength for weathered granites reaches considerable values, ranging between $47.6 \%$ and $54.0 \%$, respectively for granites PLA* (direction perpendicular to foliation) and PTA* (direction parallel to foliation). Note also the remarkable lowering of the compressive strength of granites MDB and MDB*, with high porosity, with respect to the other granites. The increase on the porosity results in the increase of the heterogeneity due to the higher amount of pores and voids. From numerical simulations, Tang et al. (2000) found that the heterogeneity plays an important role in the deformation and strength characteristics of rocks. Besides higher values of strength, more homogeneous specimens were found to deform more linearly prior to the peak stress. In this study the increase on the heterogeneity is also revealed by the higher level of nonlinearity in the stretch of the stress-volumetric diagram, see Figure 3. 

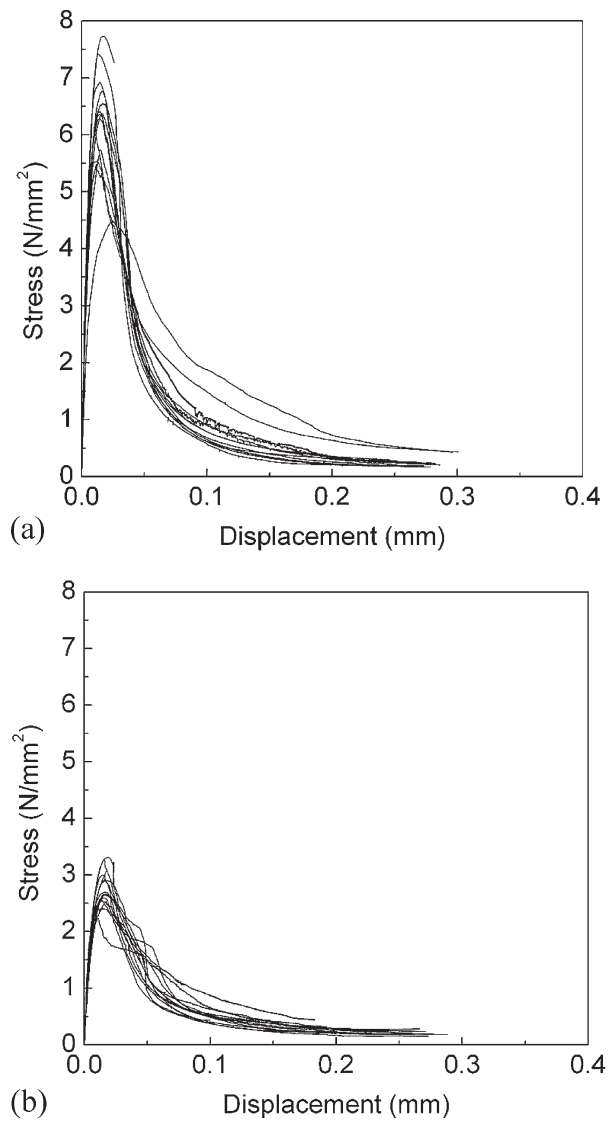

Figure 4. Force-displacement diagrams for: (a) granite PLA (parallel direction to the rift plane); (b) granite PLA* (parallel direction to the rift plane).

Figure 4 presents the complete tensile behavior of granites $\mathrm{GA}(\mathrm{a})$ and $\mathrm{GA}^{*}(\mathrm{~b})$. Similarly to compressive behavior, clear distinct pre and post-peak tensile behavior is addressed to weathered and less weathered granites. The fresh granite presents considerable higher values of the tensile strength. The load carrying capacity decrease, immediately after the peak load is reached, is abrupt and can be directly identified by the steep post-peak branch of the stress-displacement diagrams. On the contrary, in case of weathered granites, with considerable higher porosity (Tab. 3), the softening branch is much smoother. This means that the unloading of the material at the macrocrack zone is made with a larger amount of deformation. This is confirmed by the values of the normalized mode I fracture energy, $\mathrm{G}_{\mathrm{FN}}$, shown in Table 3. With the coefficient of variation indicated inside brackets. The reader is referred to Vasconcelos (2005) for further details about the calculation of the mode fracture energy. It is rather
Table 3. Normalized mode I fracture energy.

\begin{tabular}{lll}
\hline Granite & $\begin{array}{l}\mathrm{G}_{\mathrm{FN}} \\
(\mathrm{N} / \mathrm{mm})\end{array}$ & $\begin{array}{l}\text { Porosity, } \\
(\%)\end{array}$ \\
\hline $\mathrm{BA}$ & $0.023(14.7)$ & $0.51(12.9)$ \\
$\mathrm{GA}$ & $0.025(22.0)$ & $0.47(6.1)$ \\
$\mathrm{GM}$ & $0.058(23.2)$ & $3.56(2.6)$ \\
$\mathrm{RM}$ & $0.033(14.1)$ & $0.74(9.6)$ \\
$\mathrm{MC}$ & $0.043(21.0)$ & $0.87(4.3)$ \\
$\mathrm{AF} \perp \mathrm{fl}$ & $0.077(19.1)$ & $3.16(3.2)$ \\
$\mathrm{AF} / / \mathrm{fl}$ & $0.067(19.8)$ & \\
$\mathrm{MDB} \perp \mathrm{fl}$ & $0.111(17.5)$ & $5.06(7.5)$ \\
$\mathrm{MDB} / / \mathrm{fl}$ & $0.113(17.8)$ & \\
$\mathrm{MDB} * \mathrm{fl}$ & $0.147(15.7)$ & $7.24(3.4)$ \\
$\mathrm{MDB} * / / \mathrm{fl}$ & $0.126(12.1)$ & \\
$\mathrm{PTA} \perp \mathrm{fl}$ & $0.044(21.7)$ & $1.17(2.8)$ \\
$\mathrm{PTA} / \mathrm{fl}$ & $0.042(12.0)$ & \\
$\mathrm{PTA} \perp \mathrm{rp}$ & $0.151(19.4)$ & $5.02(7.6)$ \\
$\mathrm{PTA} * / / \mathrm{rp}$ & $0.124(13.6)$ & \\
$\mathrm{PLA} \perp \mathrm{rp}$ & $0.053(25.0)$ & $0.84(5.8)$ \\
$\mathrm{PLA} / / \mathrm{rp}$ & $0.040(24.6)$ & \\
$\mathrm{PLA} * \mathrm{rp}$ & $0.085(18.5)$ & $1.55(7.7)$ \\
$\mathrm{PLA} / / \mathrm{rp}$ & $0.065(13.5)$ & \\
\hline
\end{tabular}

easy to recognize the considerable increase of the normalized fracture energy on weathered granites. This is especially relevant in granite PTA and PTA*.

The pre-peak behavior also exhibits clear differences. Fresh granites present high values of the initial stiffness and the development of the nonlinear displacements up to peak load is always much less pronounced, in comparison with weathered granites, see Figure 5. Although the onset of nonlinear displacements takes place for low values of loading, close to the maximum tensile stress the growth rate is rather noticeable. This nonlinear displacement increase assumes major significance for weathered granites and, particularly, for granites with high values of porosity (MDB, MDB* and PTA*). The development of the inelastic deformation appears to be asymptotic, which can be directly connected to a pre-existing network of microfissures that can also explain such high values of the porosity found for these weathered granites.

Concerning the crack patterns obtained in direct tensile tests, it can be observed that the continuous crack-stress transfer between the two halves of the specimen, after the macrocrack is completely established, is achieved through the crack-face bridges that still connect the two halves. The main reason for such behavior is associated, on one hand, to the high number of small particles with different stiffness, and on the other hand, to the decrease of the grain boundary strength. If in granites with coarse grain size, the bridging mechanism can occur by the formation of multiple macrocracks around the coarse grains like feldspar phenocrystals (granites MC, PLA and PLA*), in 


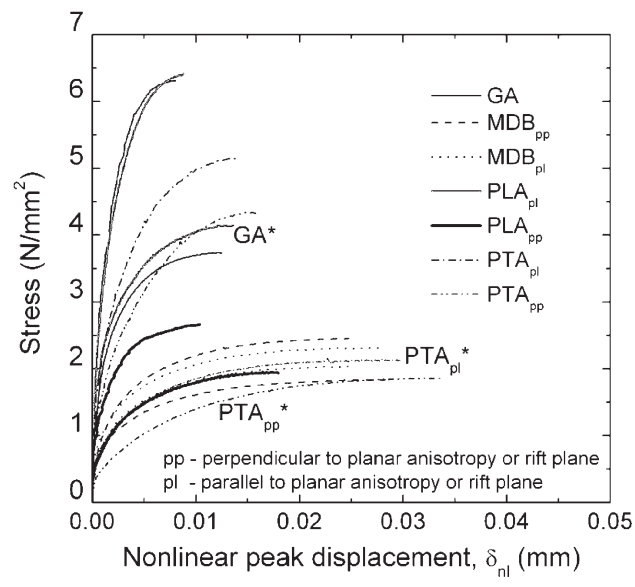

Figure 5. Development of the nonlinear displacement up to ultimate load.

medium-grained granites like $\mathrm{PTA}^{*}, \mathrm{MDB}^{*}$ or $\mathrm{AF}$, the bridging mechanism can develop around the stiffer particles that act as branches. In general, this stresstransfer or bridging mechanism is responsible, to a large extent, for the softening behavior found for other quasi-brittle materials like concrete and sandstone (Bentz et al., 1995). It is also noticed that particularly on weathered granites such as GA* and PLA*, some failures have occurred out of the notched zone according to very well defined planes. This fact confirms the major role played by the fissuring, induced by weathering effects, on the tensile fracture of granites. Similar tensile fracture took place on some specimens from granites with porphiritic internal texture, namely, granites PLA and MC, essentially due to pre-existing cleavages of the feldspar minerals. Note that in crystalline rocks such as the granites, intragranular cracks are easier to occur in some of the weaker minerals, namely feldspar and biotite (Eberhardt et al., 1999).

\subsection{Evaluation of the internal texture}

According to the results of the mechanical properties summarized in Table 2, there is a remarkable influence of the internal texture on the compressive mechanical properties and particularly on the tensile strength. This effect can also be observed through the force-displacement diagrams obtained in tensile tests for granite PLA, displayed in Figure 6. It is possible to verify that the tensile behavior is clearly dependent on the direction of the applied load. In fact, for this granite, the deformational and strength parameters assume remarkably higher values when the direction of loading is parallel to the rift plane, in comparison to the ones obtained for the perpendicular direction. Despite the
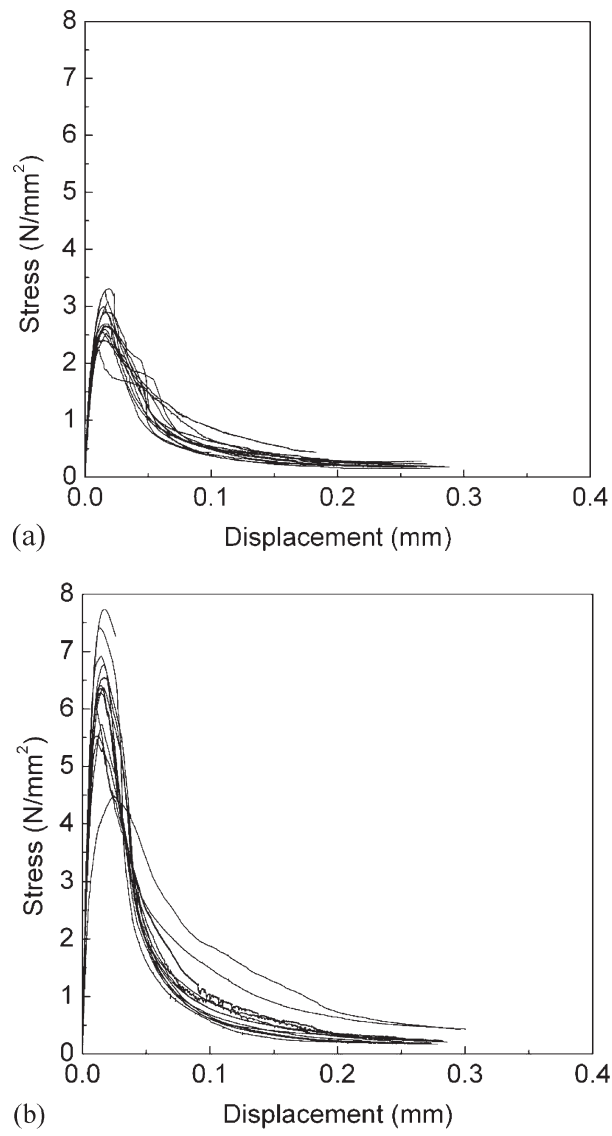

Figure 6. Stress-displacement diagrams for granite PLA; (a) direction parallel to the rift plane; (b) direction perpendicular to the rift plane.

higher values of the fracture energy found for the direction parallel to the rift plane, the ductility parameter (normalized fracture energy) exhibits larger values for the perpendicular direction, see Table 3 . This observation is in agreement with the softening shape of the stress-displacement diagram, because, in case of loading parallel to rift plane (subparallel to the flow structures), the slope of the descending branch is much steeper. The anisotropy due to internal texture is also visible in the fracture surfaces resulted from direct tensile tests. A much more tortuous fracture surfaces were found in the direction parallel to the rift plane in case of granite PLA and PLA*. The fracture surface obtained in perpendicular direction is almost flat. This behavior is followed by granites with foliation, namely PTA and AF but in a more reduced scale.

As referred in literature (Prikril, 2001; Åkesson et al., 2003), when a preferred orientation of the 

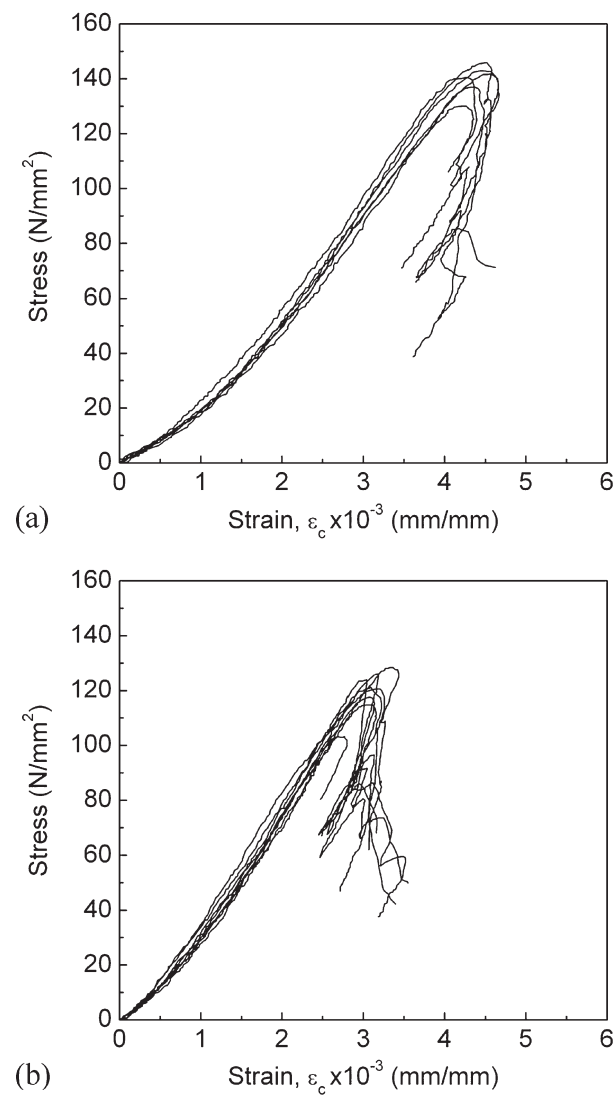

Figure 7. Stress-strain diagrams for granite PLA in compression; (a) direction perpendicular to the rift plane; (b) direction parallel to the rift plane.

feldspar phenocrystals (flow structure) or a foliation plane is clearly defined as predominant internal structure of granites, they can act as a weakness plane, which contributes to the decrease of the tensile strength on the perpendicular direction to the such anisotropy. Besides, it is possible that when coarse grains, like feldspar phenocrystals, are present, grain boundary microcracks develop around the crystals and induce such distinct properties according to the loading direction Takemura et al. (2003).

This seems to be also confirmed by the results obtained in uniaxial compression, see Figure 7. It is clear that the ascending branch of the stress-strain diagrams for the granites PLA (Fig. 7), PLA* and PTA, indicates that the extent of the initial upward concave is more pronounced when the granite is loaded in the perpendicular direction to the rift or foliation plane. The crack closure process is, therefore, more significant when the planar anisotropy is oriented in the perpendicular direction to the applied load. This anisotropic behavior is the result of a larger amount of preexisting open microcraks preferred oriented according to the foliation or the rift plane (parallel or subparallel to the flow structure). At this stage, the compressive behavior is not only affected by the solid skeleton but also by the open microcracks. The reason by which the compressive strength exhibits higher values in the direction perpendicular to the rift/foliation planes consists of the dominant brittle mechanism of compressive fracture which is based on mode I fracture, the same as in tension. Previous studies have suggested that pre-peak microcracks in compression are tensile cracks that nucleate from pre-existing flaws and propagate predominantly as mode I fracture (Lajtai et al., 1990).

Although in other scale in terms of tensile strains, when the direction of the applied load is parallel to the rift of foliation planes, the tensile strains are mostly perpendicular to the planar anisotropy. The same case occurs in the direct tensile tests when the applied load is in the direction perpendicular to the rift or foliation planes. Similar results were found in granites PTA*, MDB and MDB* respectively. With respect to the elastic properties, in general, the granites exhibit higher axial stiffness in the directions parallel to the rift or to the foliation planes. This seems to indicate that both oriented feldspar phenocrystals and biotite increase the stiffness of the material. According to Vasconcelos (2005), in these cases, smaller values of the Poisson's ratio were obtained in the direction perpendicular to the rift or foliations planes.

\section{ASSESSMENT OF THE INTERNAL TEXTURE AND WEATHERING BY SIMPLE NDT METHODS}

In the scope of using simple and economical nondestructive tests to estimate the mechanical properties of granites like ultrasonic pulse velocity and Schmidt hammer (Vasconcelos, 2007), an additional study for the assessment of these techniques as useful methods to detect anisotropy and weathering state of granites was performed. Both nondestructive tests were carried out on cubic specimens $\left(150 \times 150 \times 150 \mathrm{~mm}^{3}\right)$. Measurements of ultrasonic pulse velocity were made based on ASTM D2845 (1995) and the Schmidt hammer rebound values were obtained following the procedures indicated in ASTM D5873.

As can be seen from Figure 7, under free stress conditions, the velocity anisotropy reflects the internal structure of the material related to the preferential alignment of minerals or cracks. These results stress the role of the foliation and rift planes on the velocity of propagation of the ultrasonic waves, mainly in the following granites: AF, PTA, PTA*, PLA and PLA*. The velocity of propagation of the ultrasonic pulse velocity is always higher in the direction parallel to the 

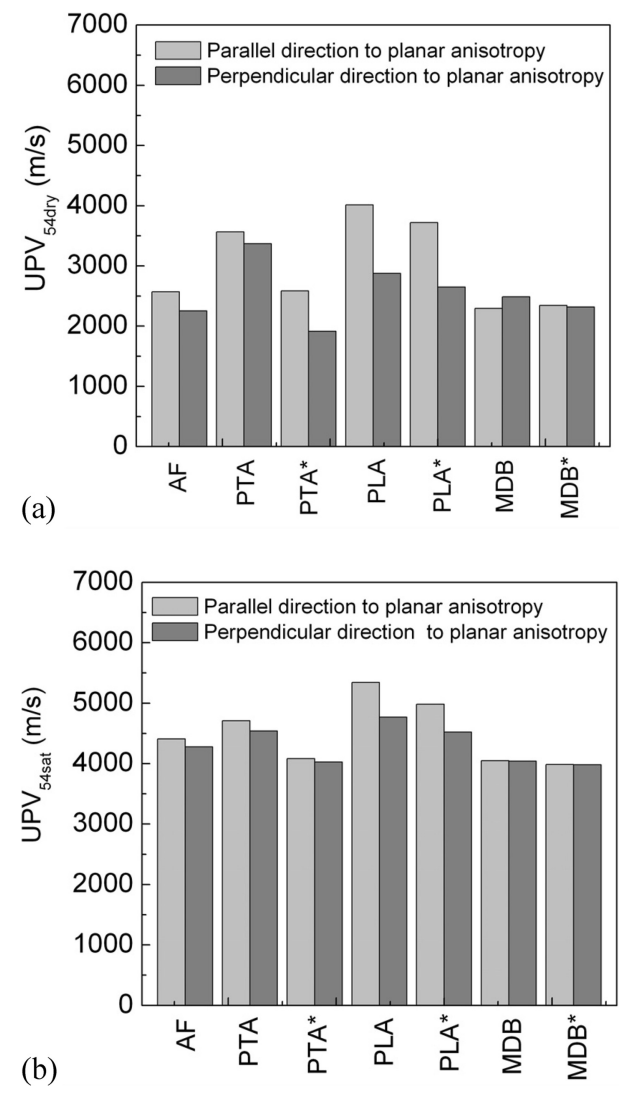

Figure 8. Evaluation of the influence of planar anisotropies on the ultrasonic pulse velocity; (a) dry cubic specimens; (b) saturated cubic specimens.

foliation or rift planes. No significant differences were found in granites MDB and MDB*, as expected. The results indicate a clear tendency for dry specimens to exhibit considerable lower values of the ultrasonic pulse velocity (UPVdry) regarding the ones obtained in saturated specimens (UPVsat). The increasing on the velocity in saturated specimens depends on the direction of measurement (with the exception of granite MDB the remaining granites), being more noticeable in the direction perpendicular to the foliation or rift planes. This characteristic is especially evident in granites PTA*, PLA, PLA*, and AF. The direct consequence of this behavior is the reduction of the anisotropy of granites under saturated conditions, which seems to be related to the loss of sensitivity for the ultrasonic pulse velocity test to detect the major discontinuity in continuum medium associated to preexisting microfissures aligned in the direction parallel to the rift plane (PLA, PLA*, PTA*) or to foliation

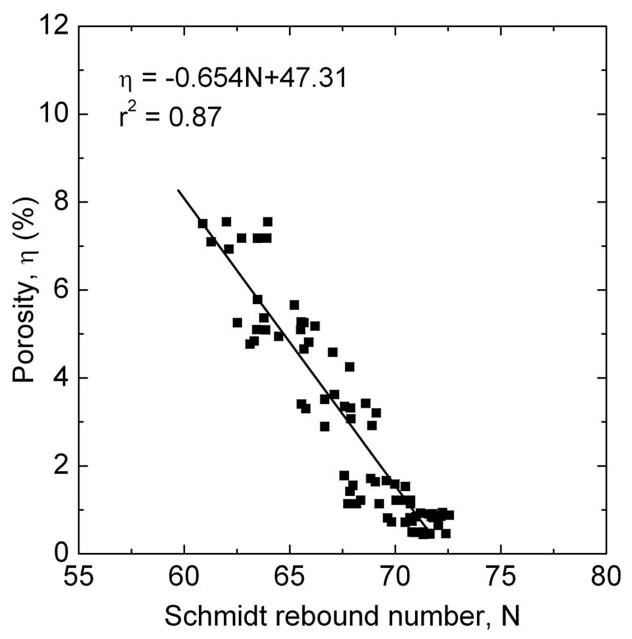

Figure 9. Relationship between Schmidt rebound number vs. porosity.

plane (AF). Therefore, the ultrasonic pulse velocity appears to be able to capture fissures aligned in the direction perpendicular to the wave propagation in dry specimens. This also justifies the deviation found between the values obtained for the UPVdry in directions parallel and perpendicular to the rift plane in case of granites PLA and PLA*. As aforementioned, the preferential alignment of the feldspar megacrystals has been aforementioned as the main source of anisotropy in granites PLA and PLA*. Additionally, the results of the UPV obtained under extreme moisture conditions suggest that anisotropy should also be related to the preferential orientation of the pre-existing microcracks. Assuming that the ultrasonic pulse velocity is highly affected by the microfissuring of the material, it can be a simple and economic tool to evaluate the degree of weathering of granites, see also Figure 8.

The Schmidt hammer rebound appears also to be a simple nondestructive method able to evaluate the weathering of the granites Vasconcelos (2005). The good relationship found between the Schimdt rebound number and the porosity, which is shown in Figure 9, reveals the variation on the porosity as the main reason by which a clear decreasing of the Schmidt rebound was found between fresh and weathered granites aforementioned. If fact, the wide variation on granite's under study is mainly associated with the different weathering levels.

\section{CONCLUSIONS}

This paper summarizes some results related to the influence of weathered state and planar anisotropy on the 
engineering properties obtained from compressive and tensile tests. It was found that considerable decrease on tensile and compressive strength as well as Young modulus is addressed to weathered granites. This work strongly suggests that heterogeneous granites can not be assumed as isotropic materials, which can have effects on the structural behavior of masonry elements. Simple non-destructive techniques appear as important methods to detect weathering levels of granites in masonry buildings.

\section{REFERENCES}

Åkesson, U., Stigh, J., Lindqvist, J.E., Göransson, M. 2004. The influence of foliation on the fragility of granitic rocks, image analysis and quantitative microscopy, Engineering Geology, 68, 275-288, 2003.

ASTM D2845. 1995. Standard test method for laboratory determination of pulse velocities and ultrasonic elastic constants of rock, American Society for Testing Materials.

ASTM D5873. 1995. Standard test method for determination of rock hardness by rebound hammer method, American Society for Testing Materials.

Bentz, D.P., Schlangen, E., Edward, J. 1995. Computer simulation of interfacial zone microstructure and its effects on the properties of cement-based composites, Materials Science of Concrete IV, J.P. Skalny and S. Mindell, Editors, American Ceramic Society, 155-199.

Eberhardt, E., Stimpson, B., Stead, D. 1999. Effects of grain size on the initiation and propagation thresholds of stress-induced brittle fractures, Rock Mechanics and Rock Engineering, 32(2): 81-99.

ISRM Suggested Methods. 1981. Suggested method for determining uniaxial compressive strength and deformability of rock materials, In: Brown E.T., ISRM Suggested Methods. Pergamon, Oxford.

Lajtai, E.Z., Carter, B.J., Ayari, M.L. 1990. Criteria for brittle fracture in compression, Engineering Fracture Mechanics, 37(1): 59-74.

Přikril, R. 2001. Some microstructural aspects of strength variation in rocks, International Journal of Rock Mechanics and Mining Sciences, 38: 671-682.

Takemura, T., Golshani, A., Oda, M., Suzuki, K. 2003. Preferred orientations of open microcracks in granite and their relation with anisotropic elasticity, International Journal of Rock Mechanics and Mining Sciences, 40: 443-454.

Tang, C.A., Liu, H., Lee, P.K.K., Tsui, Y., Tham, L.G. 2000. Numerical tests on micro-macro relationship of rock failure under uniaxial compression - Part I: effect of heterogeneity, International Journal of Rock Mechanics and Mining Sciences, 37: 555-569.

Vasconcelos, G. 2005. Experimental investigations on the mechanics of stone masonry: characterization of granites and behavior of stone masonry shear walls, PhD thesis, University of Minho, Portugal.

Vasconcelos, G., Lourenço, P.B., Alves, C.A.S, Pamplona, J. 2007. Prediction of the mechanical properties of granites by ultrasonic pulse velocity and Schmidt hammer hardness, 10th North American Masonry Conference, (accepted for publication). 
